\title{
Illusions of familiarity caused by cohort activation
}

\author{
STEPHEN A. DEWHURST and GRAHAM J. HITCH \\ Lancaster University, Lancaster, England
}

\begin{abstract}
Subjects took part in an auditory lexical decision task followed by an auditory test of recognition memory for words presented in this task. Subjects categorized their recognition judgments as based on either recollection ("remember" responses) or familiarity ("know" responses). Distractor items in the recognition test included the base words from which the nonwords used in the lexical decision task were derived. Consistent with the findings of Wallace, Stewart, Sherman, and Mellor (1995), more false alarms were made to "late" base words (where the corresponding nonwords were created by changing a phoneme near the end of the word) than to "early" base words (corresponding nonwords were created by changing a phoneme at the beginning of the word). However, this effect was found in "know" responses but not in "remember" responses. The findings are attributed to enhanced fluency with which the base words are processed following their implicit activation at encoding.
\end{abstract}

The distinction between remembering and knowing has been widely used in the study of the recollection and familiarity components of recognition memory (e.g., Conway \& Dewhurst, 1995a, 1995b; Dewhurst \& Conway, 1994; Gardiner, 1988; Gardiner \& Java, 1990, 1991; Gardiner \& Parkin, 1990; Rajaram, 1993, 1996; Roediger \& McDermott, 1995; Tulving, 1985). In a typical experiment, subjects study a set of items and are then given a test of recognition memory. For each item they recognize, they are asked to categorize it as a "remember" (R) response if they can consciously recollect details of the item's study presentation and a "know" (K) response if the item feels familiar but they cannot consciously recollect its earlier presentation. The pioneering study by Tulving (1985) found that subjects could distinguish these states of awareness, and subsequent research has supported the view that $\mathrm{R}$ and $\mathrm{K}$ responses reflect qualitatively distinct aspects of recognition memory.

Dissociable effects of a number of variables on $R$ and $K$ responses have been reported, with some variables influencing only $\mathrm{R}$ responses, others influencing only $\mathrm{K}$ responses, and other variables producing opposite effects on R and K responses (see Gardiner \& Java, 1993, and Rajaram, 1996, for reviews). Early studies suggested that $R$ responses are influenced primarily by encoding manipulations that engage conceptual processes. Thus, $R$ responses are enhanced by generation and deep levels of processing (Gardiner, 1988) and by pictures-versus-words manipulations (Rajaram, 1993), and they are inhibited by divided attention conditions at encoding (Gardiner \& Parkin, 1990) and by the tranquillizer lorazepam (Curran, Gardiner, Java, \& Allen, 1993). In contrast, K responses appear to be sensitive to manipulations of perceptual

This research was supported by Grant R000235849 from the Economic and Social Research Council of Great Britain. The authors thank the Council for its support. Correspondence should be addressed to S. A. Dewhurst, Department of Psychology, Lancaster University, Lancaster LA1 4YF, England (e-mail: s.a.dewhurst@lancaster.ac.uk). properties, since they are enhanced by masked repetition priming (Rajaram, 1993) and are inhibited by study-test modality shifts (Gregg \& Gardiner, 1994). More recent evidence, however, cannot be accounted for by the conceptual/perceptual distinction, and other theories have been proposed to account for the findings so far reported (see, e.g., Dewhurst \& Conway, 1994; Dewhurst \& Hitch, in press; Donaldson, 1996; Knowlton \& Squire, 1995; Rajaram, 1996; Yonelinas \& Jacoby, 1995).

Despite theoretical disagreement, the $\mathrm{R} / \mathrm{K}$ procedure has been used to investigate a wide range of memory phenomena. Roediger and McDermott (1995) applied this approach to the study of false memories in order to explore the experiential nature of such errors. They began by using a procedure developed by Deese (1959), in which subjects study lists of words, each of which consists of associates of a critical (nonpresented) word. Deese found that, when asked to freely recall the items in a list, subjects made a high proportion of false-recall intrusions of the critical nonpresented items on some of the lists. Roediger and McDermott replicated the study using the lists that Deese found to be the most reliable in terms of producing false recall. They then extended the procedure by giving subjects a recognition test consisting of items shown in the study lists, plus lures including the nonstudied critical items from which the lists were generated. In Experiment 1, subjects gave confidence ratings to their recognition judgments; in Experiment 2, they categorized their judgments as either $\mathrm{R}$ or $\mathrm{K}$ responses. Roediger and McDermott obtained the false-recall effect found by Deese, and they found high levels of false recognition for the nonstudied items (indeed, the false-recognition rate for the critical nonpresented items was comparable to the correct-recognition rate for the studied items, despite the fact that subjects were told to respond "old" only if they recognized the word as having been included in the original study lists).

The most surprising aspect of this finding concerned the experiential nature of the false-recognition errors in 
Experiment 2. In previous studies that used the $R / K$ paradigm, false alarms were predominantly categorized as $\mathrm{K}$ responses (see, e.g., Dewhurst \& Conway, 1994; Gardiner \& Java, 1990; Rajaram, 1993). In Roediger and McDermott's (1995) study, however, false alarms were more likely to be categorized as "remembered" than as "known," particularly when they consisted of the critical nonstudied items that subjects had falsely recalled in the previous phase of the experiment. Roediger and McDermott attributed this finding to associative responses made at encoding, by which subjects generated associates of the words they were asked to learn. Roediger and McDermott speculated that subjects need not be consciously aware of such associative responses. However, since the false-recognition errors in their study were categorized predominantly as $\mathrm{R}$ responses, Roediger and McDermott concluded that the critical nonpresented items probably did occur consciously to their subjects. They therefore interpreted the false alarms as source-monitoring errors (cf. Johnson, Hashtroudi, \& Lindsay, 1993), in that subjects may have remembered thinking about the word at study and confused this with actually hearing it.

In the present study, we further investigated the experiential nature of false memories using another encoding manipulation that has been found to increase the likelihood of false-positive recognition errors. Wallace, Stewart, Sherman, and Mellor (1995) conducted a series of experiments in which subjects were given an auditory lexical decision task, followed by a test of auditory recognition memory in which they were asked to identify the words heard in the previous phase. Each nonword in the lexical decision task was derived by changing a phoneme in a corresponding base word, and these base words were then included as lures in the recognition memory test. Wallace et al. found that subjects tended to falsely recognize the base words. The critical manipulation in their study concerned the position of the phoneme change by which the nonwords were derived. Some nonwords were derived by changing a phoneme near the beginning of a base word (e.g., faradise was derived from paradise); others were derived by changing a phoneme toward the end of the base word (e.g., paradife was also derived from paradise). It was found that subjects were more likely to falsely recognize a "late" base word (i.e., one in which the phoneme change occurred toward the end of the word) than an "early" base word (one in which the phoneme change occurred near the beginning). The effect was greater when nonwords were presented three times in the lexical decision task than when they were presented once.

Wallace et al. (1995) interpreted these findings as support for cohort models of word recognition (e.g., MarslenWilson, 1987; Marslen-Wilson \& Tyler, 1980), according to which spoken words are recognized via the activation of a set or cohort of candidate words that are consistent with incoming phonological information. Such models argue that word detectors in the cohort are gradually disqualified as incoming information unfolds over time, until only the word detector that matches the entire stimulus remains activated. Wallace et al. argued that the base words included in their recognition test were falsely recognized owing to their implicit activation during presentation of the corresponding nonwords in the lexical decision task. They suggested that the residual effects of this activation made the base words appear familiar when presented at test. That this effect was greater for late base words than for early base words was attributed to the fact the early words were disqualified at an earlier stage of the presentation of the nonword and were thus activated for shorter durations.

In the present study, we replicated the basic procedure described by Wallace et al. (1995) by giving subjects a lexical decision task, followed by a recognition memory test that included the base words from which the nonwords included in the lexical decision stage were derived. In addition, we asked subjects to label each item they recognized as either a "remember" or a "know" response. As in the study of Wallace et al., the critical manipulation was whether the phoneme change by which a nonword was derived occurred early or late in the base word. Wallace et al. found that the cohort effect was enhanced by repetition; therefore, in the present study, half of the words and nonwords were presented once, and half were presented three times. Our primary interest, however, was in exploring the experiential nature of the false memories induced by their technique. If activation of base words at encoding is implicit, then the effect reported by Wallace et al. should be observed in $\mathrm{K}$ responses but not in $\mathrm{R}$ responses.

\section{METHOD}

\section{Subjects}

The subjects were 20 undergraduate volunteers from Lancaster University, consisting of 7 males and 13 females, with a mean age of 21.4 years. They were tested individually in a quiet research cubicle and were paid for their participation. All spoke English as their first language.

\section{Stimuli and Design}

The stimuli were taken from Wallace et al. (1995) and consisted of 80 three- and four-syllable English words. Two nonwords were created from each of these base words: one by changing a phoneme early in the word (e.g., faradise was derived from paradise), and the other by changing a phoneme late in the word (e.g., paradife was derived from paradise). Sixty items appeared in each lexical decision task, consisting of 20 items presented in the form of words, 20 presented in the form of early nonwords, and 20 presented in the form of late nonwords. The remaining 20 base words were not presented in the lexical decision task, nor were either of the nonwords derived from them. Four study lists were constructed so that each item was seen by equal numbers of subjects in each condition, including the control condition. Of the 60 items used in the lexical decision task, half from each category were presented once, and half were presented three times, giving a total of 120 trials. The words and nonwords were spoken by a female speaker, who took care to ensure that the pronunciation patterns of the nonwords matched as closely as possible those of the words from which they were derived. Stimuli were recorded as sound files and presented in a random order on an Apple Macintosh computer. The subjects listened to the stimuli through headphones. 


\begin{tabular}{lccc} 
Table 1 & $\begin{array}{c}\text { T } \\
\text { Recognition of Words as a } \\
\text { Function of Repetition and Response Type }\end{array}$ \\
\hline Response & $\begin{array}{c}\text { One } \\
\text { Presentation }\end{array}$ & $\begin{array}{c}\text { Three } \\
\text { Presentations }\end{array}$ & Nonstudied \\
\hline "Remember" & .25 & .57 & .01 \\
"Know" & .26 & .23 & .06 \\
Total & .51 & .80 & .07 \\
\hline
\end{tabular}

The full set of 80 base words was used in the recognition test. Each subject therefore heard 10 words that had been presented once in the lexical decision task, 10 words that had been presented three times, 20 control words that had not been presented before, and 40 base words that had not been presented as words but from which the nonwords had been derived. Twenty of these words had been the bases for early nonwords, and 20 had been the bases for late nonwords. Of each type of base word, 10 had been presented once, and 10 had been presented three times. The 80 test items were presented in a different random order for each subject. Items in both the lexical decision task and the recognition test were presented via headphones on an Apple Macintosh computer. The dependent measures were the number of correct and false-positive $\mathrm{R}$ and $\mathrm{K}$ responses in the recognition test.

\section{Procedure}

The experiment began with the lexical decision task in which the subjects heard 40 words and 80 nonwords. The subjects were told that the experiment was concerned with linguistic processing, and they were not informed of the subsequent recognition test. They were told that they would hear a series of words and nonwords and were asked to press the "?" key if they believed an item to be a legal English word and the " $z$ " key if they believed the item to be a nonword. Each item was presented following an interval of $2 \mathrm{sec}$ after the subject's response to the previous item. The subjects were asked to repond quickly and accurately, and the task took approximately $6 \mathrm{~min}$ to complete. Following this, the subjects were involved in a nonverbal distractor task for $10 \mathrm{~min}$. They were then informed of the recognition test and given the following instructions:

In this test you will hear a series of words, some of which appeared in the lexical decision task you performed earlier and some of which are new. If you recognize a word from the earlier task please press the 1 key on the right hand side of the keyboard. If you feel that the item did not appear earlier press the 2 key. Please make this decision as quickly and accurately as you can. When you have made your response, you will see a message on the screen asking you to press either $\mathrm{R}, \mathrm{K}$, or the space bar. If you previously pressed the 2 key to indicate that you believe the word did not appear earlier, then press the space bar for the next item. However, if you pressed the 1 key to indicate that you recognize the item as having been included in the lexical decision task, please press either the R or the K key. R and K stand for "remember" and "know." These terms refer to the nature of your conscious experience as you recognize the item. A "remember" response is one in which you can consciously recollect the presentation of that item 10 minutes ago as a discrete event in your past. You may recall details of the event, such as any thoughts, feelings, or memories that came to mind when you heard the word, or an association you formed with another word in the list. A "know" response is one in which you recognize the item because it feels familiar within the context of this experiment, but you cannot recall its actual occurrence in the lexical decision task. You recognize the item purely on the basis of a feeling of familiarity. Therefore, every time you recognize a word, I would like you to press either R for remember if you can recollect specific details of the word's earlier occurrence, or $\mathrm{K}$ for know if you recognize the word at the level of familiarity but cannot recollect its actual occurrence. Please take your time over this response and think carefully about your decision for each word.

The subjects were asked to position the first and second fingers of their dominant hand on the "1" and " 2 " keys on the number pad on the right-hand side of the keyboard and to press " 1 " if they recognized the word from the lexical decision task and "2" if they believed the word did not appear in the earlier task. One second after each response, instructions appeared on the screen asking the subjects to press $\mathrm{R}, \mathrm{K}$, or the space bar. Following this response, an interval of $2 \mathrm{sec}$ elapsed prior to the onset of the next item. This was repeated until all 80 items had been presented. The subjects were asked to make the old/new decision quickly and accurately but to take as long as they required to make the $\mathrm{R} / \mathrm{K}$ decision. The subjects took approximately $5 \mathrm{~min}$ to complete the recognition test.

\section{RESULTS}

Performance in the lexical decision task was quite accurate, with $98.5 \%$ of words and $93.6 \%$ of nonwords correctly labeled. Despite this high degree of accuracy, it was decided to omit incorrectly labeled items from the analysis of the subsequent recognition data (i.e., an "old" response to a target word was counted as a hit only if the item had been correctly labeled as a word in the lexical decision task, and an "old" response to a base word was counted as a false positive only if the derived nonword had been correctly labeled as a nonword). Statistical analyses were therefore conducted on conditionalized proportions of hits and false alarms (this correction did not, however, significantly alter the main findings). The recognition test consisted of 20 items presented as words in the lexical decision task, 20 items that were the base words from which early nonwords were derived, 20 items that were the base words from which late nonwords were derived, and 20 control words not included in the lexical decision. An alpha level of .05 was used throughout the analyses reported.

Conditionalized proportions of correctly recognized words as a function of number of presentations and response type are shown in Table 1. False-alarm rates to control words are also shown. Proportions were analyzed using separate within-subjects $t$ tests for $\mathrm{R}$ and $\mathrm{K}$ responses, in which the independent variable was number of presentations (one or three). Reliably more R responses were made to words presented three times than to words presented once $[t(19)=8.72]$. No reliable effect of repetition was observed in $\mathrm{K}$ responses $[t(19)=.670]$.

The main focus in the present study, however, was on the false recognition of the base words from which the nonwords presented in the lexical decision task were derived. Particular interest was focused on the extent to which this was determined by the position of the letter change by which the nonwords were derived (early or late) and on whether any effect obtained was located in $\mathrm{R}$ or $\mathrm{K}$ responses. Table 2 shows the mean proportions of false alarms to base words as a function of position of phoneme change, number of presentations, and response type. In the analysis of false recognition, an "old" response to a base word was counted as a false alarm only if the derived nonword had been correctly labeled as a nonword in the lexical decision task. Following this adjustment, the proportions of false alarms to base words were analyzed using separate $2 \times 2$ analyses of variance (ANOVAs) for $\mathrm{R}$ and $\mathrm{K}$ responses, in which the independent variables were the position of the phoneme change (early or late) and the number of presentations of the nonwords (one or three).

No reliable effect of position of phoneme change was observed in false-positive $\mathrm{R}$ responses $(F<1)$. However, 
Table 2

False Recognition of Base Words as a Function of Position of Phoneme Change, Repetition, and Response Type

\begin{tabular}{|c|c|c|c|c|}
\hline \multirow[b]{2}{*}{ Response } & \multicolumn{2}{|c|}{ Early } & \multicolumn{2}{|c|}{ Late } \\
\hline & $\begin{array}{c}\text { One } \\
\text { Presentation }\end{array}$ & $\begin{array}{c}\text { Three } \\
\text { Presentations }\end{array}$ & $\begin{array}{c}\text { One } \\
\text { Presentation }\end{array}$ & $\begin{array}{c}\text { Three } \\
\text { Presentations }\end{array}$ \\
\hline "Remember" & .01 & .10 & .03 & .11 \\
\hline “Know" & .13 & .14 & .17 & .20 \\
\hline Total & .14 & .24 & .20 & .31 \\
\hline
\end{tabular}

a significant effect of position of phoneme change was observed in $\mathrm{K}$ responses, with the subjects making more false-positive $\mathrm{K}$ responses to base words from which late nonwords were derived than to base words from which early nonwords were derived $\left[F(1,19)=5.80, M S_{\mathrm{e}}=\right.$ $0.048 ; M \mathrm{~s}=.18$ and .13 , respectively]. More false-positive $\mathrm{R}$ responses were made when derived nonwords were presented three times than when they were presented once $\left[F(1,19)=16.6, M S_{\mathrm{e}}=0.149 ; M \mathrm{~s}=.11\right.$ and .02 , respectively]. In contrast, false-positive $\mathrm{K}$ responses were not reliably influenced by the repetition of derived nonwords $(F<1.1)$. The interaction between position of phoneme change and number of presentations was not significant in either $\mathrm{R}$ or $\mathrm{K}$ responses.

Analysis across the 80 test items, rather than across the 20 subjects, yielded similar results. Since the repetition of study items was a between-groups factor, the data were analyzed via mixed $2 \times 2$ (number of repetitions $\times$ position of phoneme change) ANOVAs on the numbers of correct recognition judgments for each item. In the analysis of $\mathrm{R}$ responses, a reliable effect of repetition was observed $\left[F(1,39)=27.9, M S_{\mathrm{e}}=8.56\right]$, with more false-positive $\mathrm{R}$ responses following three presentations of a study item than following a single presentation. No reliable effect of position of phoneme change was observed in $\mathrm{R}$ responses $(F<1.9)$. In contrast, a reliable effect of position of phoneme change was observed in $\mathrm{K}$ responses $\left[F(1,39)=4.702, M S_{\mathrm{e}}=2.50\right]$, with more false-positive $\mathrm{K}$ responses to base words from which late nonwords were derived than to base words from which early nonwords were derived. No reliable effect of repetition of study items was found in $\mathrm{K}$ responses $(F<1)$.

Some false alarms were made to control words (i.e., words presented as lures in the recognition test that did not form the bases of nonwords in the lexical decision task; see Table 1). In order to compare the false recognition of base words with that of control words, additional one-way ANOVAs were carried out on $\mathrm{R}$ and $\mathrm{K}$ responses, in which the independent variable was type of word (early base word, late base word, or control). Since the manipulation of number of presentations was meaningless for the control words, base words were collapsed across this variable. Planned comparisons showed that fewer false-positive $\mathrm{R}$ responses were made to control words than to either early words $[t(19)=2.47]$ or late words $[t(19)=3.12]$. Similarly, fewer false-positive $\mathrm{K}$ responses were made to control words than to either early words $[t(19)=3.51]$ or late words $[t(19)=5.50]$.

\section{DISCUSSION}

Wallace et al. (1995) found that subjects were more likely to make a false-recognition error to a previously unheard word when it was the base of a nonword heard in a prior lexical decision task. Furthermore, this effect was greater when nonwords were created by changing a phoneme toward the end of the base word than when they were created by changing a phoneme at the beginning of the base word. The present study replicated these findings (see total false alarms in Table 2) and, in addition, showed that the cohort effect is located in the familiarity component of recognition memory, as measured by "know" $(\mathrm{K})$ responses. Some evidence of an effect of prior activation in "remember" $(R)$ responses was found in that more false-positive $R$ responses were made to base words than to control words. However, false-positive $\mathrm{R}$ responses to base words were not reliably influenced by the position of the phoneme change.

The present findings are of particular interest in view of the relatively small number of variables that have been found to selectively influence $K$ responses. Early studies suggested that $K$ responses were sensitive to manipulations of perceptual characteristics of stimuli, whereas R responses were sensitive to operations that engaged conceptual processes. However, more recent findings cannot be accounted for in terms of a conceptual/perceptual distinction. For example, using a picture recognition task, Rajaram and Coslett (1992) found that $K$ responses were greater when the size of a stimulus at test was different from its size at study. This is inconsistent with the view that $\mathrm{K}$ responses reflect perceptual processes, given that such a view predicts that $\mathrm{K}$ responses would benefit from perceptual congruence between study and test presentations.

Rajaram (1996) proposed a distinctiveness-fluency framework to account for the findings so far observed using the $\mathrm{R} / \mathrm{K}$ procedure. According to this account, any encoding manipulation that highlights the distinctive or salient attributes of a stimulus will subsequently enhance $\mathrm{R}$ responses. Conversely, manipulations that increase fluency of processing on the second presentation of an item, such as masked repetition priming (Rajaram, 1993) and study-test modality matches (Gregg \& Gardiner, 1994), will enhance K responses. The effects of cohort activation on $\mathrm{K}$ responses in the present study are consistent with the fluency component of this account. Findings from priming studies indicate that the identification of an item is facilitated following a prior presentation (e.g., Jacoby, 1983; Jacoby \& Dallas, 1981). The present findings indicate that this priming effect is obtained when a test item is not itself presented at study but is contained in the cohort activated in response to a nonword derived from the test item. Nonstudied items are implicitly activated in the cohort of items generated in response to the nonwords, and this activation enhances the fluency with which they are processed when subsequently presented in a recognition test. This enhanced fluency gives rise to an illusion of familiarity for the nonstudied item (cf. Jacoby \& Whitehouse, 1989).

This illusion can be explained by the attributional account of familiarity proposed by Jacoby and his colleagues (e.g., Jacoby, 1988; Jacoby, Kelley, \& Dywan, 1989; Jacoby \& Whitehouse, 1989). Central to 
this account is the notion that familiarity is determined by the fluency with which an item is processed, and this in turn is influenced by the goal that is set by the subject. When an item is presented in a test of memory, any enhancement of fluency is attributed to a prior presentation of an item, and the subjects experience a feeling of familiarity for that item. When an item is presented in a task that does not involve explicit memory, such as judging temporal duration, then enhanced fluency is attributed to factors relevant to the task, such as a longer exposure duration, and the item is not experienced as familiar. The present findings can be explained by such an account by assuming that the implicit activation of the base words in response to the nonwords derived from them enhances the fluency with which they are later processed at test. Because the base words are presented within the context of a test of recognition memory, the enhanced fluency is attributed to prior presentation, and the words are experienced as familiar.

Roediger and McDermott (1995) also found high levels of false alarms following the presentation of associates of the nonstudied items (cf. Deese, 1959). However, in contrast to the present study, the false alarms found by Roediger and McDermott were typically categorized as $\mathrm{R}$ responses. One possible explanation of the difference in subjective experience of the false alarms reported by Roediger and McDermott and those found in the present study is that the experiential nature of false-recognition errors is determined by whether or not subjects are consciously aware of generating the items at study. In the two experiments described by Roediger and McDermott, subjects saw multiple items that were high associates of the same nonstudied items. It is possible that the presentation of multiple associated items increased the likelihood of the nonstudied items occurring consciously to subjects at encoding, thereby increasing the likelihood that false recognition will be associated with recollection. This is consistent with the finding from the present study that false-positive $R$ responses increased when the corresponding nonwords were presented three times rather than once.

These findings indicate that the position of the phoneme change and repetition are not additive but represent independent effects, with the former influencing familiarity and the latter influencing recollection We have argued that late phoneme changes enhance false-positive $K$ responses by increasing the fluency with which the base words are processed at test. The finding that false-positive $\mathrm{K}$ responses are not influenced by repetition is consistent with findings that repetition does not enhance perceptual priming beyond the effect found with a single presentation (e.g., Challis \& Sidhu, 1993). However, this begs the question of why repetition and the position of the phoneme change have different effects on conscious awareness. One possible reason is that each repetition of a nonword occurred in a different context, thereby increasing the discriminability of individual presentations (this is consistent with Rajaram's (1996) view that R responses are enhanced by the distinctiveness of encoding events). However, since context did not change appreciably during the period of implicit activation, $R$ responses were not enhanced by the longer periods of activation that occurred with late nonwords relative to early nonwords.

To summarize, we have found that illusions of familiarity can be created by implicit activation at study. Using a procedure developed by Wallace et al. (1995), nonstudied items were falsely recognized when they were the base words from which nonwords presented at study were derived. As was found by Wallace et al., this effect was greater when the nonwords were created by changing a phoneme near the end of a word than when they were created by changing a phoneme near the beginning of the word, consistent with cohort theory (MarslenWilson, 1987; Marslen-Wilson \& Tyler, 1980). Moreover, the present findings indicate that this effect is due to enhanced familiarity of the base words, since the false alarms created using this procedure were predominantly categorized as $\mathrm{K}$ responses. However, $\mathrm{K}$ responses were not reliably influenced by the repetition of derived nonwords These findings are consistent with the view that the familiarity of an item in a test of recognition memory is determined by the fluency with which it is processed. In contrast, $\mathrm{R}$ responses were influenced by repetition, but not by the position of the phoneme change by which nonwords were derived. This is consistent with Rajaram's (1996) hypothesis that recollection is influenced by the distinctiveness of the initial encoding event. The double dissociation between the effects of posi- tion of phoneme change and repetition thus provides further support for the $R / K$ distinction and illustrates the value of the $R / K$ procedure in separating effects that may otherwise appear to be interdependent.

\section{REFERENCES}

Challis, B. H., \& Sidhu, R. (1993). Dissociative effect of massed repetition on implicit and explicit measures of memory. Journal of Experimental Psychology: Learning, Memory, \& Cognition, 19, 115-127.

Conway, M. A., \& Dewhurst, S. A. (1995a). Remembering, familiarity, and source monitoring. Quarterly Journal of Experimental Psychology, 48A, 125-140.

Conway, M. A., \& Dewhurst, S. A. (1995b). The self and recollective experience. Applied Cognitive Psychology, 9, 1-19.

Curran, H. V., Gardiner, J. M., Java, R. I., \& Allen, D. (1993). Effects of lorazepam on recollective experience in recognition memory. Psychopharmacology, 40, 309-313.

DEESE, J. (1959). On the prediction of occurrence of particular verbal intrusions in immediate recall. Journal of Experimental Psychology, 58, 17-22.

Dewhurst, S. A., \& Conway, M. A. (1994). Pictures, images, and recollective experience. Journal of Experimental Psychology: Learning, Memory, \& Cognition, 20, 1088-1098.

Dewhurst, S. A., \& HiTch, G. J. (in press). Cognitive operations and recollective experience in recognition memory. Memory.

DONALDSON, W. (1996). The role of decision processes in remembering and knowing. Memory \& Cognition, 24, 523-533.

Gardiner, J. M. (1988). Functional aspects of recollective experience. Memory \& Cognition, 16, 309-313.

GARDINER, J. M., \& JAVA, R. I. (1990). Recollective experience in word and nonword recognition. Memory \& Cognition, 18, 23-30.

Gardiner, J. M., \& JAva, R. I. (1991). Forgetting in recognition memory with and without recollective experience. Memory \& Cognition. 19, 617-623.

Gardiner, J. M., \& Java, R. I. ( 1993). Recognizing and remembering. In A. F. Collins, S. E. Gathercole, M. A. Conway, \& P. E. Morris (Eds.), Theories of memory (pp. 163-188). Hillsdale, NJ: Erlbaum.

Gardiner, J. M., \& PARKIN, A. J. (1990). Attention and recollective experience in recognition memory. Memory \& Cognition, 18, 579-583.

GregG, V. H., \& Gardiner, J. M. (1994). Recognition memory and awareness: A large effect of study-test modalities on "know" responses following a highly perceptual orienting task. European Journal of Cognitive Psychology, 6, 131-147.

JACOBY, L. L. (1983). Perceptual enhancement: Persistent effects of an experience. Journal of Experimental Psychology: Learning, Memory, \& Cognition, 9, 21-38.

JACOBY, L. L. (1988). Memory observed and memory unobserved. In U. Neisser \& E. Winograd (Eds.), Remembering reconsidered: Ecological and traditional approaches to the study of memory (pp. 145177). Cambridge: Cambridge University Press.

JACOBY, L. L., \& DALLAS, M. (1981). On the relation between autobiographical memory and perceptual learning. Journal of Experimental Psychology: General, 110, 306-340.

Jacoby, L. L., Kelley, C. M., \& Dywan, J. (1989). Memory attributions. In H. L. Roediger III \& F. I. M. Craik (Eds.), Varieties of memory and consciousness: Essays in honour of Endel Tulving (pp. 391-422). Hillsdale, NJ: Erlbaum.

JACOBY, L. L., \& Whitehouse, K. (1989). An illusion of memory: False recognition influenced by unconscious perception. Journal of Experimental Psychology: General, 118, 126-135.

Johnson, M. K., Hashtroudi, S., \& Lindsay, D. S. (1993). Source monitoring. Psychological Bulletin, 114, 3-28.

KNowlton, B. J., \& SQuire, L. R. (1995). Remembering and knowing: Two different expressions of declarative memory. Journal of Experimental Psychology: Learning, Memory, \& Cognition, 21, 699-710.

MARSLEN-Wilson, W. D. (1987). Functional parallelism in spoken word recognition. Cognition, 25, 71-102.

Marsien-Wilson, W. D., \& Tyler, L. K. (1980). The temporal structure of spoken language understanding. Cognition, 8, 1-71.

RaJARAM, S. (1993). Remembering and knowing: Two means of access to the personal past. Memory \& Cognition, 21, 89-102. 
Rajaram, S. (1996). Perceptual effects on remembering: Recollective processes in picture recognition memory. Journal of Experimental Psychology: Learning, Memory, \& Cognition, 22, 365-377.

Rajaram, S., \& Coslett, H. B. (1992, November). Further dissociations between "remember" and "know" judgments in recognition memory. Poster presented at the 33rd Annual Meeting of the Psychonomic Society, St. Louis

RoEdiger, H. L., III, \& MCDermott, K. B. (1995). Creating false memories: Remembering words not presented in lists. Journal of Experimental Psychology: Learning, Memory, \& Cognition, 21, 803-814.

Tulving, E. (1985). Memory and consciousness. Canadian Psychologist, 26, 1-12.
Wallace, W. P., Stewart, M. T., Sherman, H. L., \& Mellor, M. D. (1995). False positives in recognition memory produced by cohort activation. Cognition, 55, 85-113.

Yonelinas, A. P., \& JACOBY, L. L. (1995). The relation between remembering and knowing as bases for recognition: Effects of size congruency. Journal of Memory \& Language, 34, 622-643.

(Manuscript received January 31, 1997; revision accepted for publication June 12, 1997.) 